\title{
Koronavirüs (COVID-19) ile Yeni Dijital Dünyada Değişen Tüketici Tercihleri
}

\author{
DOI: 10.26466/opus.829515
}

*

\begin{abstract}
Talha Bayır *
* Öğr. Gör. Dr., Şırnak Üniversitesi, Şırnak/Türkiye E-Posta: talhabayir@sirnak.edu.tr

ORCID: $\quad \underline{0000-0002-3897-9205}$

\section{Öz}

Koronavirüs (COVID-19)'ün dünya genelinde hızl yayılımı, küresel düzeyde dijital bir mücadelenin başlamasına neden olmuştur. Bu dönemde yapılan araştırmalarda, tüketicilerin eskiye oranla mutfakta çok daha fazla zaman geçirdiği, hobilerine ve kişisel bakımlarına ise daha fazla zaman ayırdıkları gözlemlenmiştir. COVID-19 nedeniyle yaşanan korku ve endişe, insanın hayatını idame ettirmek adına market ve gıda sektörüne yönelimini sağlamıştır. Karantina önlemleri sebebiyle de tüketiciler, alışverişlerini ağırlıklı olarak online platformlar üzerinden gerçekleştirmeye başlamışlardır. Bu tür sanal ticaret ortamlarn ile dijital ekonomi platformları oluşturmuş ve tüketicilere, her an her yerden alışveriş yapma imkan tanınmıştır. İşletmeler ise bu süreçte tüketicilerle iletişim kurma tekniklerini yeniden gözden geçirmişlerdir. Bireylerin evde geçirdikleri süre, bazı sektörlerde reklam harcamalarının artmasına neden olurken; markaların dijital reklam için ayırdıkları bütçeler ise düşmüştür. Bu araştırma ile amaçlanan; COVID-19 sürecinde yaşanan gelişmelerin, dijital mecralara ve e-ticarete olan etkisini karşllaştırmalı olarak sunmaktır. Ayrıca bu süreçteki işletmeler ile tüketicilerin davranış şekilleri incelenerek, COVID-19'un ticari hayata olan etkileri ve farklı ürün gruplarında olan talep değişiklikleri değerlendirilmiştir.
\end{abstract}

Anahtar Kelimeler: Koronavirüs (COVID-19), Dijital Medya, Dijital Pazarlama, E-Ticaret, Tüketici Davranışları. 
ISSN:2528-9527

E-ISSN : 2528-9535

YIl Year: 11

Cilt Volume: 17

Sayı Issue :Pandemi Özel Sayısı

Nisan April 2021

\title{
Changing Consumer Preferences in the New Digital World with Coronavirus (COVID-19)
}

\begin{abstract}
The quick spread of coronavirus (COVID-19) across the world has caused a digital struggle to begin at a global level. In the researches conducted in this period, it was observed that consumers spent much more time in the kitchen compared to the past, and more time spent on their hobbies and personal care. The fear and anxiety experienced due to COVID-19 has made people tend to the market and food sector in order to survive. Due to the quarantine measures, consumers have started to make their purchases mainly on online platforms. Digital economy platforms have been created with such virtual commerce environments and consumers have been given the opportunity to shop from anywhere at any time. Businesses, on the other hand, have reviewed their communication techniques with consumers in this process. While the time people spend at home causes an increase in advertising expenditures in some sectors; Brands' budgets for digital advertising have decreased. The aim of this research is; To present the effects of the developments in the COVID-19 process on digital channels and e-commerce in a comparative manner. In addition, by examining the behavior patterns of businesses and consumers in this process, the effects of COVID-19 on commercial life and demand changes in different product groups were evaluated.
\end{abstract}

Keywords: Coronavirus (COVID-19), Digital Media, Digital Marketing, E-Commerce, Consumer Behavior. 


\section{Giriş}

Koronavirüs (COVID-19), dünya üzerindeki birçok ülkeye hızlı bir yayılım göstermiştir. COVID-19 nedeniyle bir yandan sağlık endişesi duyulurken, diğer yandan ise iş hayatı devam ettirilmek zorunda kalınmıştır. Bu süreçte, COVID-19 nedeniyle birçok işletme klasik çalışma şekillerini değiştirmiş ve dijital ortamlara geçiş yapmıştır. Dijital platformlardan biri olan online alışveriş siteleri, COVID-19 sürecinin de en önemli aktörleri arasında yerini almıştır. Kriz olarak da nitelendirilebilecek bu dönemde hem işletmeler hem de tüketiciler için e-ticaret, büyük bir sıçrama yapmıştır. Karantina ve sosyal mesafe gibi kavramlar ile birlikte değişen yaşam tarzı tüketim davranışlarını da değiştirmiştir.

İletişim teknolojileri, tüketicilerin tüketim davranışlarının ve alışveriş kanallarının (e-ticaret, mobil ticaret vb.) da farklılaşmasına neden olmuştur. Bu doğrultuda gelişen internet ekonomisi ile işletmeler, rekabette önemli bir avantaj elde etmiştir. Bu sayede e-ticaret, büyük Pazar payı fırsatları sunan, yeni nesil bir sanal platform olarak konumlanmıştır (Cui vd., 2017, s. 10; Kayapınar vd., 2017, s. 473). Bu tür sanal ticaret ortamları ile dijital ekonomi platformları oluşturmuş ve tüketicilere, oturduğu yerden alışveriş şansı tanınmıştır (Sin vd., 2012, s. 326). Hızla gelişen e-ticaret aracılığıyla online alışveriş, mal ve hizmet satın alımlarında, popüler bir hal almıştır. TÜBİSAD ve Deloitte (2019) tarafından, e-ticaret sektör büyüklükleri sırasıyla; perakende dışı işlemler için 28,4 milyar TL, perakende işlemleri için ise 31,5 milyar TL olarak raporlanmıştır. Bu rakamlar COVID-19 süreciyle ise katlanarak büyümüştür. Andrienko (2020)'ye göre bu dönemde, Amazon ve Ebay gibi iki büyük eticaret sitesi yaklaşık 5,5 milyon tüketiciye ulaşmıştır. Temassız ödeme yönteminin ise geçen yıla göre yaklaşık 3 katına çıtığ 1 ve sadece 2,5 milyon adet temassız kartın da ilk kez kullanıldığını açıklanmıştır (Değirdöğmez, vd., 2010, s. 130).

$\mathrm{Bu}$ araştırma ile amaçlanan; COVID-19 sürecinde yaşanan gelişmelerin, dijital mecralara ve e-ticarete olan etkisini dair karşılaştırmalı bilgiler sunmaktır. Ayrıca bu dönemde işlemeler ile tüketicilerin davranışları incelenerek, COVID-19'un ticari hayata olan etkileri ve farklı ürün gruplarında olan talep değişiklikleri değerlendirilecektir. 


\section{COVID-19 ve Dijital Medya}

COVID-19 virüsünün ortaya çıtığ 1 ilk günden itibaren dijital medya oldukça önemli bir rol oynamıştır. Kamuoyunun virüsün etkileri ile ilgili bilinçlendirilmesi ve toplumsal davranışların yönlendirilmesi açısından dijital medya araçları etkin bir şekilde kullanılmıştır. Dünya ülkelerinin bu süreçte aldığ toplumsal düzenlemeler ve kısitlamalara dair tüm kararlar, dijital medya aracllı̆̆ıyla takip edilmiştir (Erdoğan, 2020, s. 1309). Dünya ülkelerinin COVID19 'un yayılmasını önlemeye yönelik uygulamaları ile "home ofis" sistemine geçilmiştir. Bu sayede uzaktan çalışma hizmeti veren dijital platformlar, kullanıcı sayılarını sadece bir hafta içerisinde $\% 25$ ten fazla arttırmıştır. Ayrıca, WhatsApp gibi uygulamaların kullanım oranı ise yaklaşık üç kat artıs göstermiştir. Son olarak, evde eğitim/iş hayatı uygulamaları, internet kullanımını \%90 oranında arttırmıştır (Değirdöğmez, vd., 2010, s. 131). Tablo 1'de COVID-19 süresince tüketicilerin kullanmış oldukları dijital kanallar gösterilmiştir.

Tablo 1. COVID-19 süresince tüketicilerin kullanmış olduklarn dijital kanallar

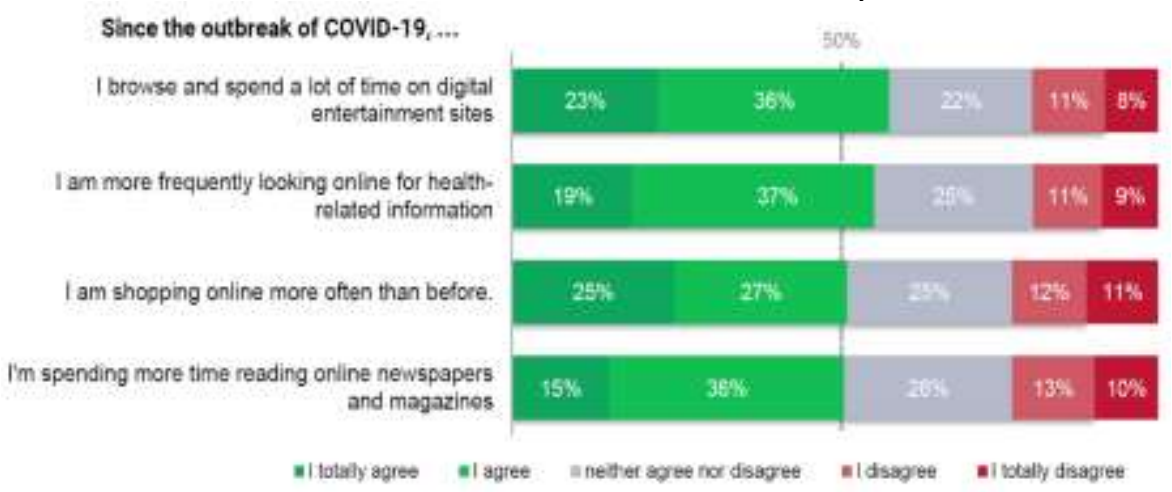

Netcomm Suiesse (2020)

Tablo 1'deki veriler incelendiğinde, COVID-19 süresince bireylerin; \%59 oranında dijital eğlence platformlarına, \%56 oranında sağllkla ilgili bilgileri aramaya, $\% 52$ oranında daha fazla online alışveriş yapmaya ve $\% 51$ oranında ise gazete ve magazin haberlerini okumaya vakit ayırdıkları gözlemlenmiştir. COVID-19 sürecindeki hayata geçirilen uygulamalar, insanların alışveriş yöntemlerini ve işletmelerin dijital kanal yatırımlarını da etkilemiştir. Örneğin; COVID-19 mücadele sürecinde bazı markaların sürece destek vermek 
adına reklamlarında, bazılarının ise logo güncellemesine giderek, farkındalık yarattıkları görülmüştür. COVID-19 döneminde en çok vurgulanan noktalardan biri olan "sosyal mesafe" temalı logo güncellemeleri, Volkwagen, Audi, Mercedes, McDonalds ve Coca Cola gibi markalar tarafından yapılmıştır. $\mathrm{Bu}$ tür bir hamle ile ilgili firmalar, marka kimliğinin önemli bir parçası olan logoları, sosyal mesafeye dikkat çekmek için bir marka stratejisi olarak kullanmışlardır. Böylelikle, markanın görünürlüğünü, bilinilirliğini ve değerini arttırarak tüketicini zihninde bir konumlandırma yaratmak hedeflenmektedir (Erdoğan, 2020, s. 1310). Tablo 2'de COVID-19 süresince tüketicilerin kullanmış oldukları dijital iletişim platformları gösterilmiştir.

Tablo 2. COVID-19 süresince tüketicilerin kullanmış oldukları dijital iletişim platformlart

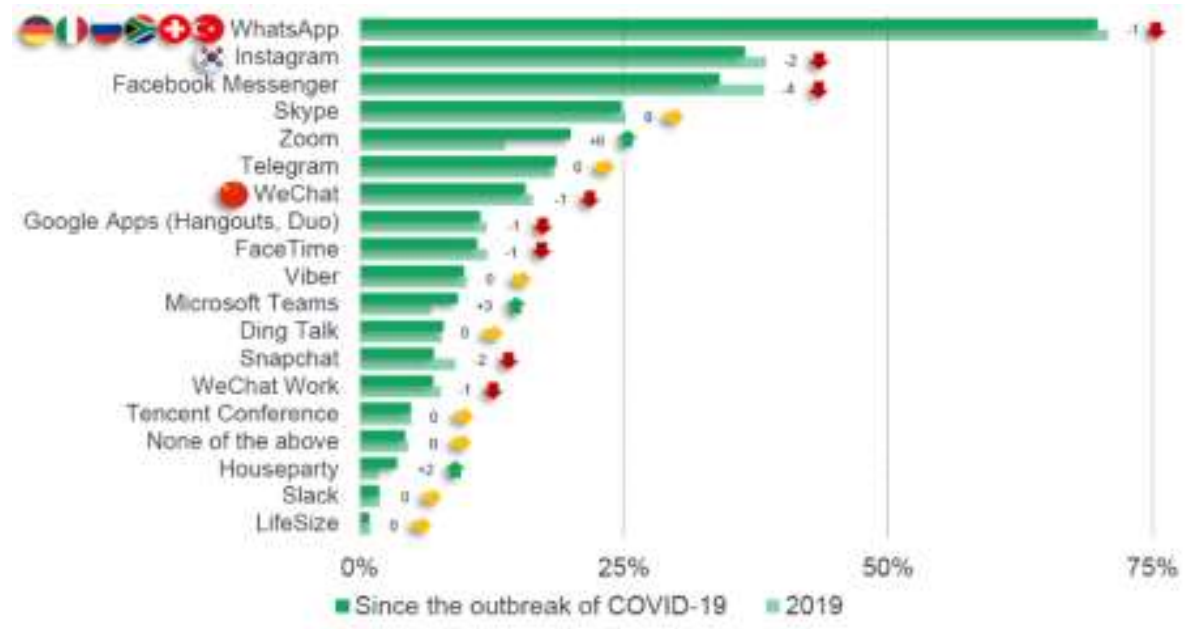

Netcomm Suiesse (2020)

COVID-19 ile dünyada dijital dönüşüm hızlanmış ve işletmeler faaliyetlerini sürdürmek için uzaktan çalışma uygulamalarına geçiş yapmıştır. Bu dönemde, Zoom, Skype, Teams vb. uzaktan çalışma uygulamaları, işletmeler tarafından sıklıkla kullanmaktadırlar. Tablo 2'deki veriler incelendiğinde, COVID-19 süresince bireylerin ağırlıklı olarak; WhatsApp, Instagram ve Facebook Messenger'ı kullandıkları gözlemlenmiştir. Ayrıca bu dönemde, uzaktan çalışma sistemlerinden biri olan Zoom uygulamasının kullanımında önemli bir artış olmuştur. Tablo 3'te COVID-19 süresince tüketicileri online satın alımlara yönlendiren dijital medya kanalları gösterilmiştir. 
Tablo 3. COVID-19 süresince tüketicileri online satın alımlara yönlendiren dijital medya kanallan

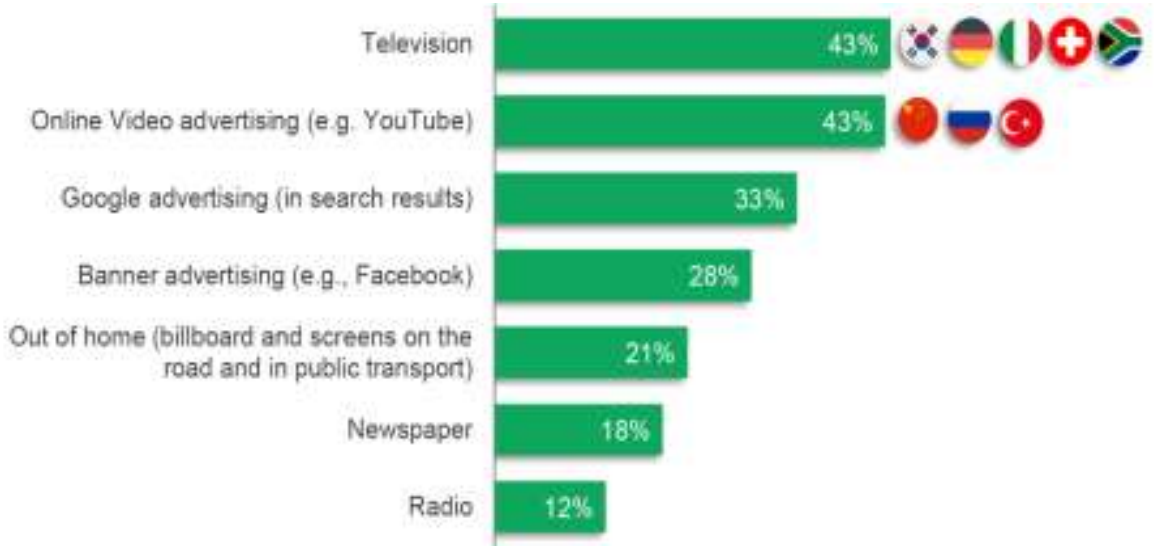

Netcomm Suiesse (2020)

COVID-19 sürecindeki uygulamalar, işletmelerin reklam yatırımlarını da etkilemiştir. Birçok işletmenin geçici olarak hizmet verememesi nedeniyle reklam yatırımları düşerken; bazı sektörlerde ise reklam harcamaları artmıştır. Örneğin; markaların dijital reklam için ayırdıkları bütçelerin bu dönemde \%23,5 oranında azalmıştır (Erdoğan, 2020, s. 1310). World Advertising Research Center (WARC) verilerine göre, COVID-19'dan önce küresel reklam yatırımları 2020'nin ilk döneminde yüzde 7,1 oranında büyüme göstermiştir. Ancak daha sonra, özellikle zamanının büyük bölümünü evde geçiren tüketiciler için markalar, reklam bütçelerini geleneksel medya araçları yerine, online mecralara aktarmaları gerektiğini fark etmişlerdir. Bu nedenle de, geleneksel medya mecralarında reklam yatırımlarında düşüş yaşanmıştır. Küresel reklam yatırımlarındaki bu daralma \%8,1 ile yaklaşık 50 milyar dolar olduğu tahmin edilmektedir (Erdoğan, 2020, s. 1311). Tablo 3 'teki veriler incelendiğinde, COVID-19 süresince bireylerin; \%43 oranında Televizyon ve Online Video Reklamları, \%33 oranında ise Google Reklamlar aracılığ alışverişe yöneldikleri gözlemlenmiştir.

\section{COVID-19 ve E-Ticaret}

COVID-19 döneminde, dijitalleşme sürecini tamamlamış olan işletmeler yeni tüketim sistemine hızlıca entegre olmuşlardır. İnternet kullanımının günlük 
yaşam üzerinde etkisi ve çevrimiçi faaliyetlere olan eğilim, e-ticaret sektörünün de büyüme göstermesine neden olmuştur (Akgün, vd., 2020, s. 435). Eticaretin bu dönemdeki hacimsel olarak büyümesinin temel nedenleri arasında; ürün çeşitliliği, karşılaştırma yapma imkanı, kampanya ve indirimler, zaman ve mekan gibi kısıtlamaların olmayışı, ödeme kolaylığı ve genel olarak pratik olma özellikleri siralanabilir (Erdoğan, 2020, s. 1304). Bu doğrultuda, COVID-19 sürecinde tüketicilerin davranışları da hızlı bir değişim göstermiştir. Tüketicilerin güdüleri, tüketim kararları, neye maruz kaldıkları ve nasıl algıladıkları üzerinde etkilidir (Torun Kayabaşı, 2020, s. 21). Bu bilgiler ışığında Amerika, Kanada, İngiltere, Fransa ve Almanya da bulunan tüketiciler üzerinde gerçekleştirilen bir araştırmada, COVID-19 sürecinde dört farklı tüketici profilinin ortaya çıtığı bulgulanmıştır (Rogers ve Cosgrove, 2020):

- Stoklayan Tüketiciler (\%35): COVID-19 sürecinde endişeli olan ve enharcamalarını en çok market sektöründe yapan tüketicilerden oluşmaktadır.

- Tedbirci Tüketiciler (\%27): 45 yaşın üzerinde, COVID-19 sürecinde en zor yaşayan ve en az harcama yapan, "gelecek" için kötümser olan tüketicilerden oluşmaktadır.

- Stabil Tüketiciler (\%26): Tüketim alışkanlıklarında pek bir değişiklik olmaya ve COVID-19 sürecinden çok etkilenmeyen tüketicilerden oluşmaktadır.

- Garantici Tüketiciler (\%11): 18-44 yaş aralığında, COVID-19 süresince endişeli olan ve "gelecek" için iyimser olan tüketicilerden oluşmaktadır.

Günümüzde fiziki mağazası olan birçok işletmenin, online alışveriş siteleri de mevcuttur. Tüketiciler mağazaları dolaşarak fiyat ve özellik karşılaştırmaları yapmak yerine, online alışveriş siteleri üzerinden fiyat ve özellik karşılaştırmalarını yaparak satın alma daha kolay bir hale dönüştürebilmektedirler (Telli Danışmaz, 2020, s. 84). Online alışveriş platformlarının sağlamış oldukları bu tür avantajlar, tüketicilerin karantina ve sosyal mesafe dönemlerinde tüketim alışkanlıklarına da yansımıştır. Tablo 4'te COVID-19 süresince tüketicilerin online alışveriş sitelerini ziyaret etme sıklıkları gösterilmiştir. 
Tablo 4. COVID-19 süresince tüketicilerin online alışveriş sitelerini ziyaret etme sıklıklar

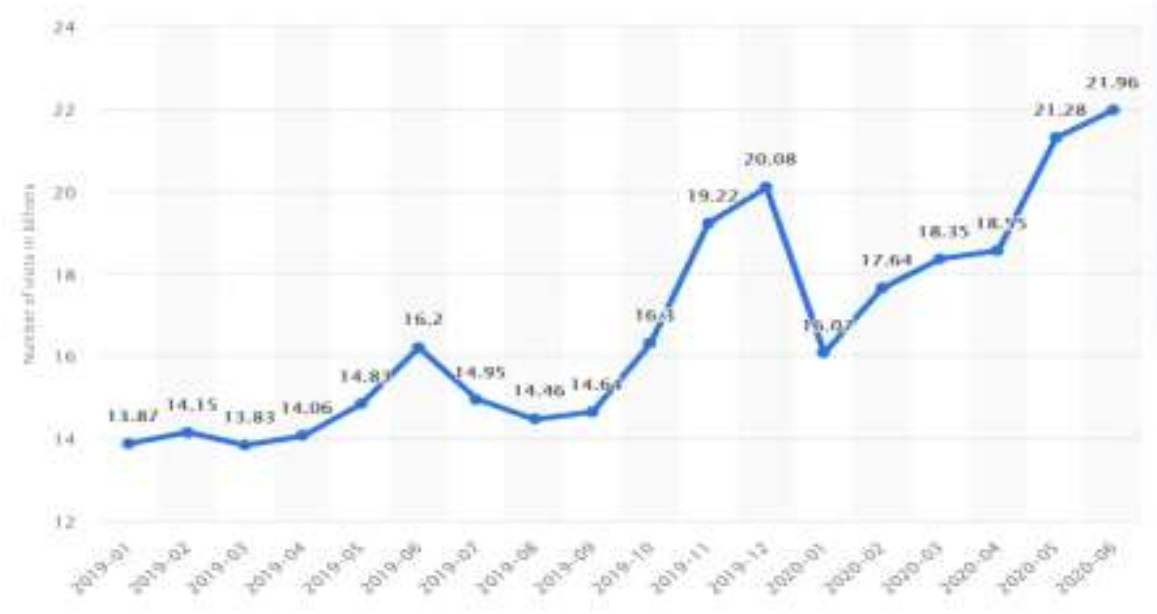

Statista (2020)

Tablo 4 'teki veriler incelendiğinde, online alışveriş sitelerini ziyaret etme sıklıkları, COVID-19 vakalarının başlangıç tarihlerine paralel olarak eylül ayı itibariyle yükselişe geçmiştir. Alınan karantina önlemleri neticesinde aralık ayı içerisinde yeni normalleşme süreci ile ise, online alışveriş sitelerini ziyaret etme sıklıkları azalmıştır. Daha sonra hem yeni normalleşme hem de ikinci dalga riski sebebiyle online alışveriş sitelerinin ziyaret etme sıklıkları paralel bir şekil de artmaya devam etmiştir. Tablo 5 'te COVID-19 süresince en çok satı̧ yapan e-ticaret siteleri gösterilmiştir.

Tablo 5. COVID-19 süresince en çok satış yapan e-ticaret siteleri

\begin{tabular}{lll}
\hline Sira No & E-Ticaret Siteleri & Milyon \\
\hline $\mathbf{1}$ & Amazon.com & $4059 \mathrm{M}$ \\
\hline $\mathbf{2}$ & Ebay.com & $1227 \mathrm{M}$ \\
\hline $\mathbf{3}$ & Rakuten.co.jp & $804 \mathrm{M}$ \\
\hline $\mathbf{4}$ & Samsung.com & $648 \mathrm{M}$ \\
\hline $\mathbf{5}$ & Walmart.com & $614 \mathrm{M}$ \\
\hline $\mathbf{6}$ & Appel.com & $562 \mathrm{M}$ \\
\hline $\mathbf{7}$ & Aliexpress.com & $532 \mathrm{M}$ \\
\hline $\mathbf{8}$ & Etsy.com & $395 \mathrm{M}$ \\
\hline $\mathbf{9}$ & Homedepot.com & $292 \mathrm{M}$ \\
\hline
\end{tabular}

Andrienko (2020) 
COVID-19 süresince insanlar dışarı çıkmaktan korkmakta, sosyal mesafelerini korumakta ve ihtiyaçlarını evden yani online olarak yapmaktadırlar. $\mathrm{Bu}$ dönemde online market alışverişleri \%74 oranında artmış ve en çok satın alınan ürünler arasında; tuvalet kağıdı, tek kullanımlık eldivenler, dondurucu, çay, kahve ve ekmek makinaları, bulmaca ve boyama kitapları, hava difüzörleri ve spor aletleri (koşu bandı, bisiklet, yoga matı, egzersiz topu vb.) kendini göstermiştir (Bhatti, 2020, s. 1450). Tablo 5'teki veriler incelendiğinde ise; Amazon ve Ebay gibi iki büyük e-ticaret sitesinin yaklaşık 5,5 milyon tüketiciye ulaştığ 1 görülmektedir. Tablo 6' da COVID-19 süresince gelişen ekonomilerde meydana gelen değişimler gösterilmiştir.

Tablo 6. COVID-19 süresince gelişen ekonomilerde meydana gelen değişimler Since the outbreak of COVID-19, I am shopping more often online than before.

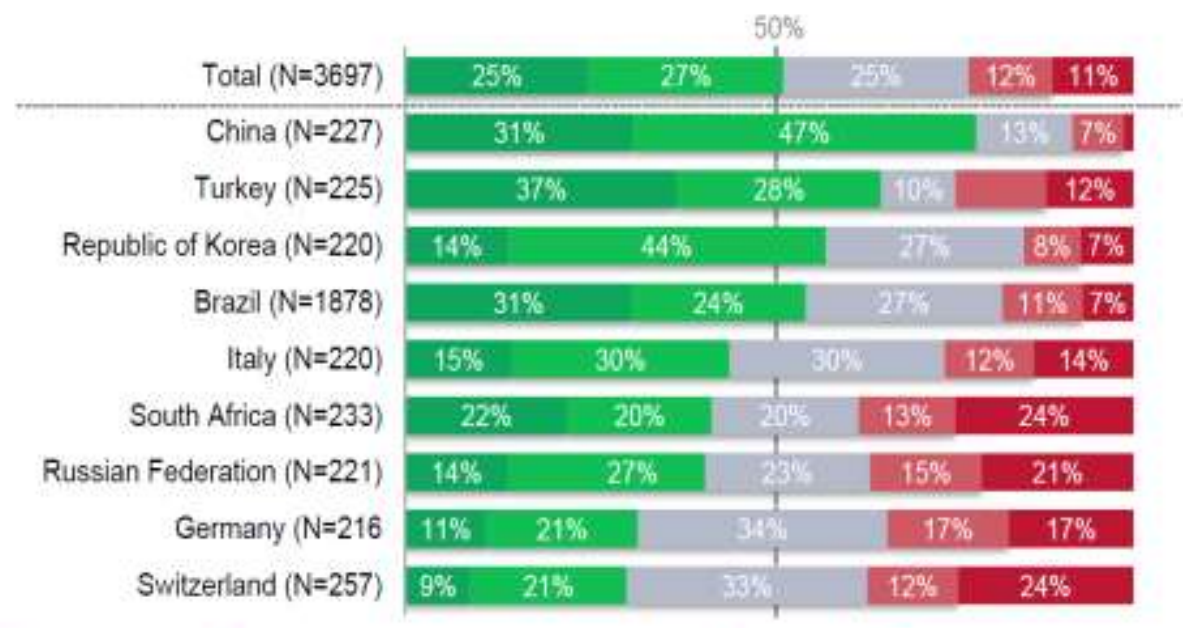

"I totaly agree $\quad$ | agree $\quad$ neither agree nor disagree in disagree $\quad$ | | totally disagree

Netcomm Suiesse (2020)

Online alışveriş, geleneksel pazara bir alternatif olarak algılanmakta ve gezmeden, yorulmadan ve sıkılmadan alışveriş yapma fırsatı tanımaktadır. İşletmeler açısından bakıldığında ise, web siteleri ve mobil uygulamalar üzerinden oluşturulan online mağazalar sayesinde yüksek ciro ve düşük maliyet sunmaktadır (Armağan ve Temel, 2018, s. 623). Bu doğrultuda tablo 6'daki veriler incelendiğinde, COVID-19 süresince bireylerin, eskiye oranla online 
ticareti daha sık yaptıkları ortaya konmuştur. Bu verilere göre COVID-19 süresince Çinli tüketiciler $\% 78$, Türk tüketiciler $\% 65$ ve Koreli tüketiciler ise $\% 58$ oranında online alışverişlerini arttırdıkları gözlemlenmiştir. Tablo 7'de COVID-19 bazı ülkelerde meydana gelen e-ticaret hacmi değişimleri gösterilmiştir.

\section{Tablo 7. COVID-19 bazı ülkelerde meydana gelen e-ticaret hacmi değişimleri}

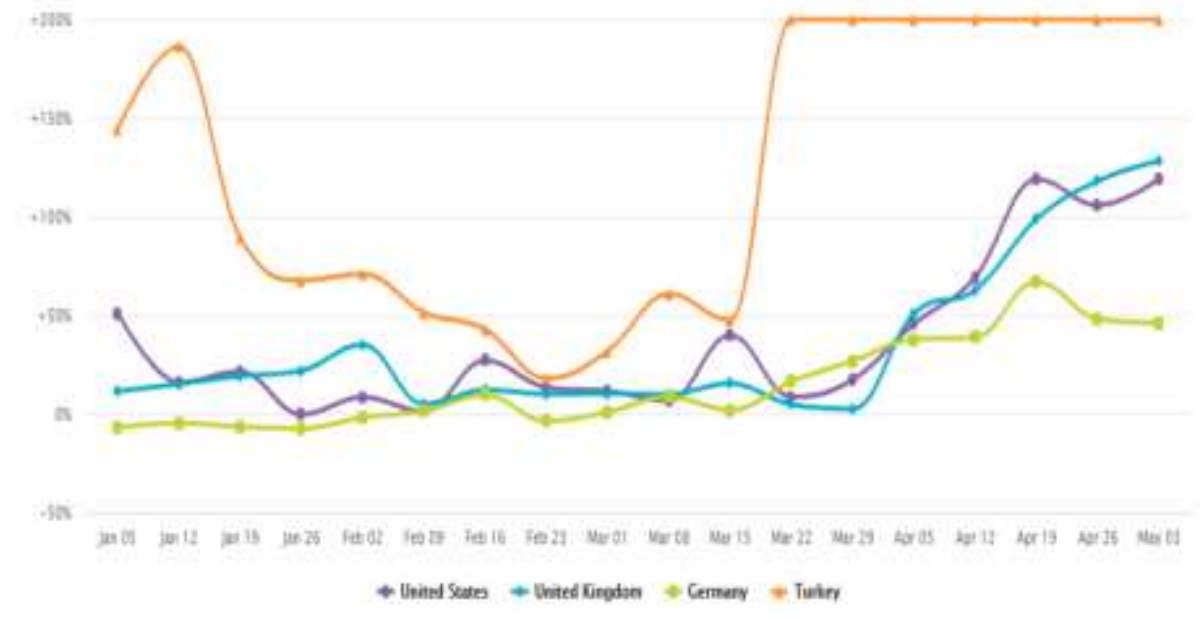

Güven (2020)

Tablo 7'deki veriler incelendiğinde, Amerika, İngiltere, Almanya ve Türkiye arasında, ilk vakanın görüldügü 11 Mart'tan sonra, Türkiye de önemli bir artış görülmüştür. Bu artış daha sonraları \%200'lere kadar varmıştır. Almanya' da karantina önlemlerinin zayıflamasıyla artışlar görülmeye başlanmıştır. Amerika ve İngiltere' de ise 15 Mart'a kadar inişli çıkışlı bir dalgalanma olmasına karşın, karantina sürecine girilmesi itibariyle online alışveriş yapan tüketicilerin sayısı artmaya başlamıştır (Güven, 2020, s. 256). Tablo 8'de COVID-19 süresince online satın alımlarda tercih edilen teslimat şekilleri gösterilmiştir. 
Tablo 8. COVID-19 süresince online satın alımlarda tercih edilen teslimat şekilleri

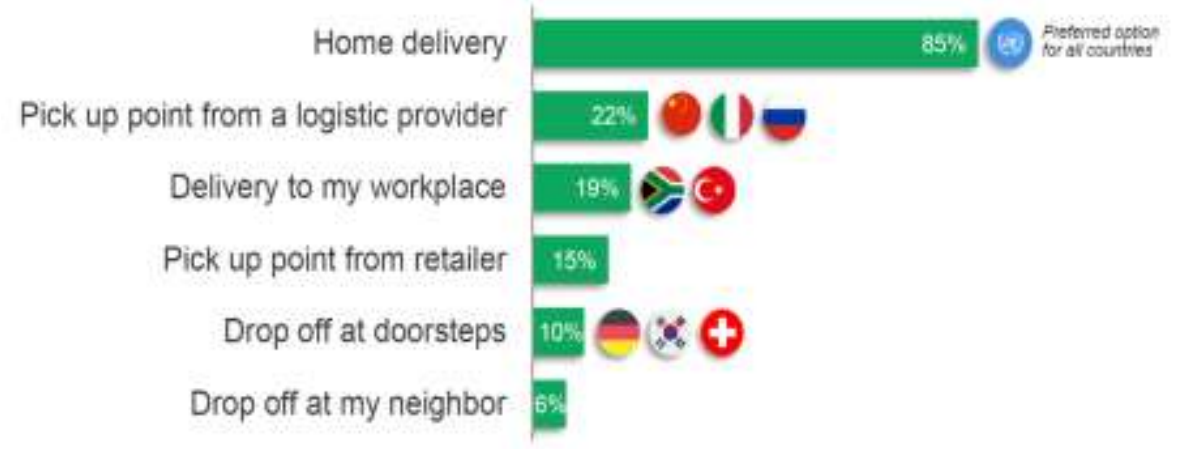

Netcomm Suiesse (2020)

E-ticaretin sürdürülebilirliği için lojistik ve tedarik hizmetlerin verimli ve etkin kullanımı önem arz etmektedir. COVID-19 süresince ürünlerin kargoyla teslimatında büyük aksamalar yaşanmaktadır. Bu tür kriz anlarında teslimatların gecikmemesine dair gerekli önlemler, perakendeciler ve kargo firmaları tarafından ileriki dönemde planlanmalıdır. Tablo 8' deki veriler incelendiğinde, COVID-19 süresince bireylerin online alışveriş siteleri aracıllğ 1 ile satın aldıkları ürünlerin teslimatını; \%85 oranında evlerine, \%22 oranında kargo firmalarına, \%19 oranında ise iş yerlerine istedikleri gözlemlenmiştir. Tablo 9'da google üzerinden yapılan "teslimat" aramaları gösterilmiştir.

Tablo 9. Google üzerinden yapılan "teslimat" aramaları (şubat-nisan, 2020)

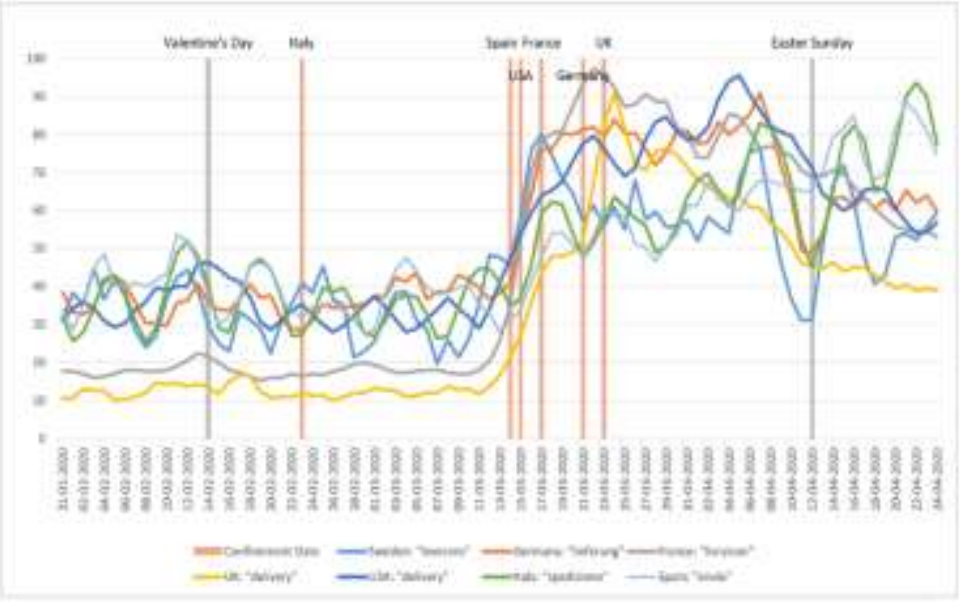

$O E C D(2020)$ 
COVID-19 vakalarının Avrupa da ciddi manada görüldüğü ilk ülkelerden biri olan İtalya'nın almış olduğu karantina önlemlerinin hemen ardından, eticarette yaşanan artışlar sırasıyla, Asya-Pasifik ülkeleri ve Avrupa ile Kuzey Amerika da kendini göstermiştir (tablo 9). Ayrıca, Almanya ve İngiltere gibi karantina önlemlerinin henüz alınmadığg ülkelerde ise o aylarda dahi Google üzerinden "teslimat" aramalarının neredeyse iki katına çıktığ1 görülmüştür. Bu durum, hükümet eylemlerinin, tüketici davranışlarında yarattığı etkiyi net bir şekilde göstermektedir. Tablo 10' da COVID-19 süresince online satış1 artan ürün kategorileri gösterilmiştir.

Tablo 10. COVID-19 süresince online satışı artan ürün kategorileri $\mathrm{s}$ of active online shoppers conducting at least one online purchase every 2 months

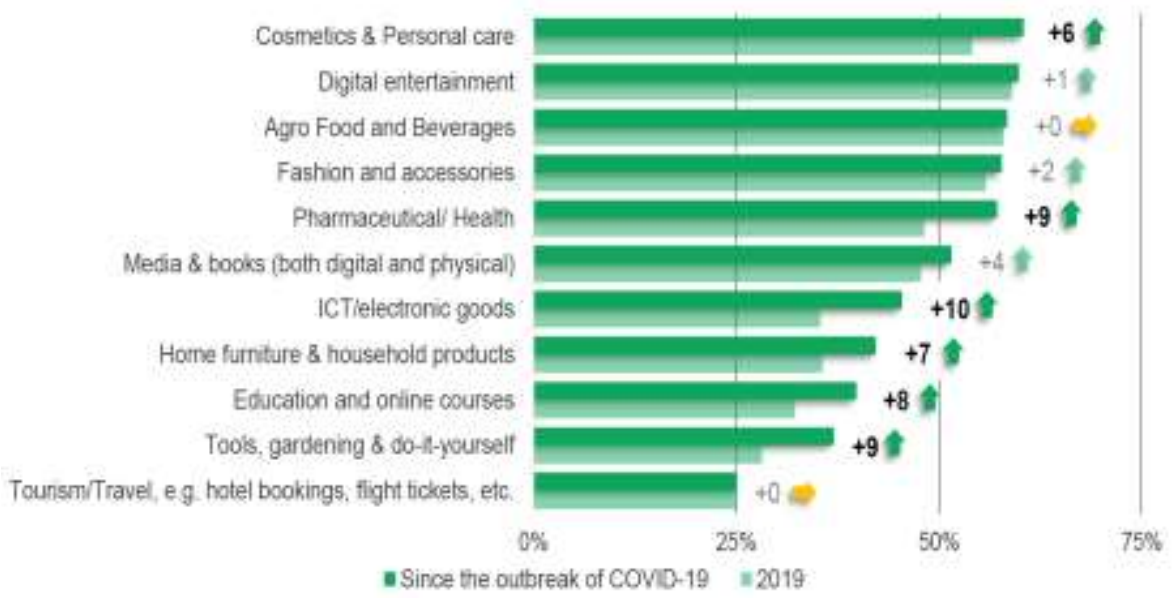

Netcomm Suiesse (2020)

Tablo 10'daki veriler incelendiğinde, COVID-19 süresince bireylerin online alışveriş siteleri aracılığı ile satın aldıkları ürün kategorilerinde çeşitli artışların yaşandığı görülmüştür. Bu doğrultuda sırasıyla; elektronik, sağlık, araç-gereç, eğitim, mobilya ve kozmetik gibi ürün kategorileri artış gösterenler arasında yer almaktadır. Tablo 11'de COVID-19 süresince online satın alımlarda kullanılan ödeme yöntemleri gösterilmiştir. 
Tablo 11. COVID-19 süresince online satın alımlarda kullanılan ödeme yöntemleri

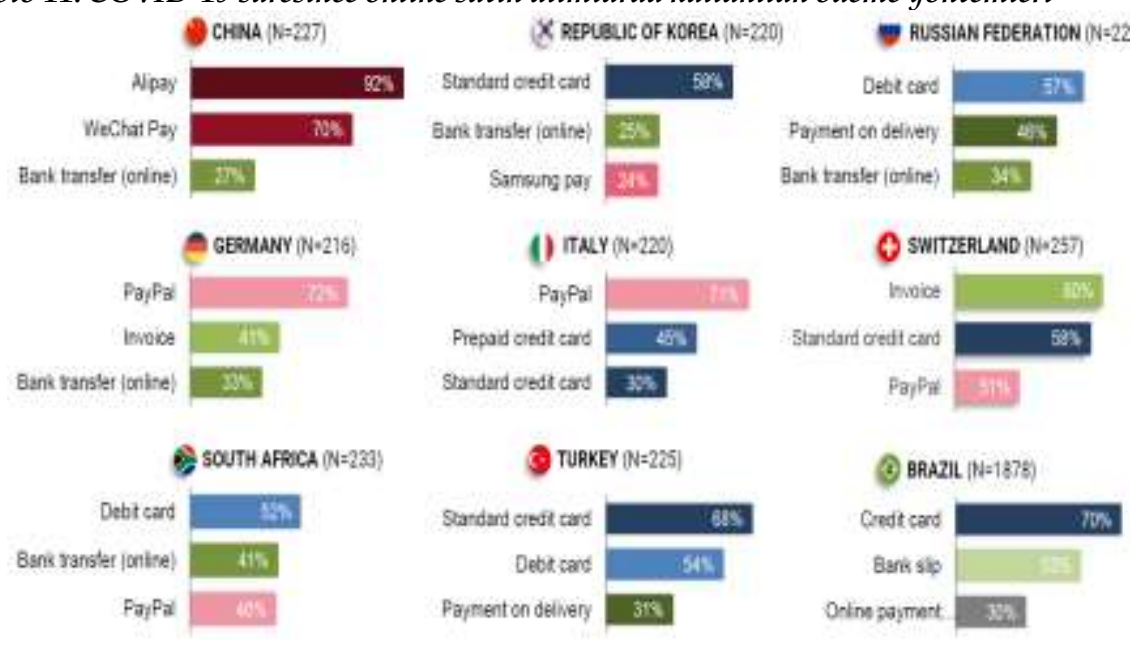

Netcomm Suiesse (2020)

COVID-19 süresince, temassız ödeme işlemlerin önem kazandığı görülmektedir. Bunun nedenleri arasında ilgili virüsün, temas yoluyla ve kâğıt paralar ile bulaş riski taşımasıdır. Temas olmadan sipariş oluşturma ve teslimat sistemlerinin hayata geçirilmesi, online satın alma sürecini de hızlandırmaktadır (Akgün, vd., 2020, s. 444). BKM (Bankalararası Kart Merkezi)’ye göre temassız ödemeler, geçen yıla göre yaklaşık 3 kat artmıştır. Yine bu dönemde, 2,5 milyon adet temassız kart ise ilk defa kullanılmıştır (Değirdöğmez, vd., 2010, s. 130). Tablo 11'deki veriler, COVID-19 süresince ülkelerin farklı ödeme yöntemlerine başvurduklarını göstermektedir. Bu verilere göre Türk tüketiciler, \%68 oranında kredi kartı, \%54 oranında banka kartı ve \%31 oranında ise kapıda ödeme seçeneğini kullanmaktadırlar.

\section{Sonuç ve Öneriler}

COVID-19'un dünya ülkeleri arasında hızlı yayılımı, global anlamda bir mücadelenin başlamasına neden olmuştur. Korku ve endişeye kapılan birçok insan ise hayatını idame ettirme paniği ile market ve gıda sektöründe artışa neden olmuştur. Bu gibi nedenler, online alışveriş ile e-ticaret sektöründe yaşanan artışın göstergelerindendir. Online alışverişler, mekânsal ve ödeme açısından bir temas gerektirmemesi, özellik ve fiyat kıyaslamaları sunması ve pratik olması açısından avantajlar sağlamaktadır. Araştırma doğrultusunda, 
OECD (2020)'nin e-ticaret raporundan hareketle, COVID-19' dan kaynaklı olarak e-ticarette yaşanan gelişme ve öneriler şu şekilde sıralanabilmektedir:

- COVID-19 krizi, e-ticaretin yeni firmalara, müşterilere ve ürün türlerine doğru genişlemesini hızlandırmıştır. Müşterilere, evlerinden çok çeşitli ürünlere erişim fırsatı sağlarken; işletmeler ise, sosyal mesafe kısıtlamaları önlemlerine rağmen faaliyetlerini sürdürme imkanı tanımıştır.

- Ülkeler arası farklılıklara rağmen, COVID-19 krizi ülkeler genelinde eticaret ortamında dinamizmi arttırmış ve e-ticaretin kapsamını yeni firmalar, tüketici segmentleri ve ürünler dahil olmak üzere genişlemesini sağlamıştır.

- COVID-19 krizi neticesinde, e-ticaretin bireyler ve firmalar için bu tür yeni rolleri sebebiyle yeni politik düzenlemelere de ihtiyaç duyulmaktadir.

- Tüketicilerin e-ticarete katılım yolunda ön yargılarını oluşturan; iletişim, finansal erişim, dijital güvenlik ve mahremiyet, kişisel bilgilerin korunması gibi konularda bir deneyim ve rahatlama yaşanmıştır.

- E-ticaret ortamındaki bu değişikliklerin birçoğu, salgının yeniden dalgalanma olasılığı ve online satın alma alışkanlıklarının rahatlığı gibi faktörler nedeniyle kalıcı bir hal alacaktır.

- Bu bilgilerin yanı sira, COVID-19 sirasinda ve sonrasında e-ticaret'e dair uygulanabilecek öneriler şu şekilde sıralanabilmektedir:

- Dijital Pazar bölümleri arasındaki farkı kapatmak amacıyla kaliteli, indirimli ve güvenli ürün grupları kırsal kesimlere doğru genişletilmelidir.

- Savunmasız tüketici gruplarını (yaşlılar vb.) haksız iş uygulamalarından ve güvenli olmayan ürünlerden koruyarak, e-ticaret faaliyetlerine katılımı sağlanmalıdır.

- Yenilikçi e-ticaret iş modellerinin oluşturulmasını ve online iş uygulamalarının esnek kalması sağlanmalıdır.

- E-ticarette yasal belirsizlikleri azaltıp, bilgi paylaşımı ile şeffaflığı arttırılmalıdır.

- KOBİlerin, e-ticarete güvenini arttırmak ve yeni satış alanları sunmak için yasal ve finansal teşvikler sağlanmalıdır. 
COVID-19'dan kaynaklı olarak e-ticarette yaşanan değişimler ve sonrasında uygulanabilecek öneriler bahsedilmiştir. Online alışveriş firmaları lehine gelişen bu değişimlerin iyi analiz edilip, stratejiler geliştirilmesi ileriki vadede kazanç sağlayacaktır. 


\title{
EXTENDED ABSTRACT
}

\section{Changing Consumer Preferences in the New Digital World with Coronavirus (COVID-19)}

\author{
Talha Bayır \\ Şırnak University
}

Coronavirus (COVID-19) has spread rapidly to many countries around the world. While health concerns were raised due to COVID-19, on the other hand, business life had to be continued. In this process, due to COVID-19, many businesses have changed their traditional way of working and switched to digital environments. Online shopping sites, one of the digital platforms, have taken their place among the most important actors of the COVID19 process. In this period, which can also be described as a crisis, e-commerce has made a great leap forward for both businesses and consumers. Along with concepts such as quarantine and social distance, the changing lifestyle has also changed consumption behaviors.

Communication technologies have caused the consumption behavior of consumers and shopping channels (e-commerce, mobile commerce, etc.) to differ as well. With the internet economy developing in this direction, businesses have gained a significant advantage in competition. In this way, ecommerce is positioned as a new commercial virtual asset that offers great market share opportunities (Cui et al., 2017, p. 10; Kayapınar et al., 2017, p. 473). It has created digital economy platforms with such virtual commerce environments and consumers have been given the opportunity to shop from anywhere at any time (Sin et al., 2012, p.326). Through the rapidly developing e-commerce, online shopping has become a popular tool for purchasing goods and services. In the e-commerce report published in cooperation with TÜBİSAD and Deloitte (2019), sector sizes are respectively; It is stated as 28.4 billion TL for non-retail transactions and 31.5 billion TL for retail transactions. These numbers have grown exponentially with the COVID-19 process. According to Andrienko (2020), two major e-commerce sites such as Amazon and Ebay reached approximately 5.5 million consumers during this period. It has been announced that the contactless payment method has nearly tripled 
compared to last year and only 2.5 million contactless cards were used for the first time (Degirdöğmez, et al., 2010, p.130).

Today, many businesses that have physical stores also have online shopping sites. Instead of making price and feature comparisons by browsing through the stores, consumers can make purchasing easier by making price and feature comparisons on online shopping sites (Telli Danışmaz, 2020, p.84). Such advantages provided by online shopping platforms are also reflected in the consumption habits of consumers during quarantine and social distance periods. In this period, online market shopping increased by $74 \%$ and among the most purchased products; toilet paper, disposable gloves, freezer, tea, coffee and bread machines, puzzle and coloring books, air diffusers and sports equipment (treadmill, bicycle, yoga mat, exercise ball, etc.) showed themselves (Bhatti, 2020, p.1450). During this period, two major ecommerce sites such as Amazon and Ebay reached approximately 5.5 million consumers. During COVID-19, Chinese consumers increased their online shopping by $78 \%$, Turkish consumers by $65 \%$ and Korean consumers by $58 \%$.

In the COVID-19 period, businesses that have completed the digitalization process have quickly integrated into the new consumption system. The effect of internet use on daily life and the trend towards online activities caused the e-commerce sector to grow as well (Akgün, et al., 2020, p.435). Among the main reasons for the volumetric growth of e-commerce in this period; Product diversity, possibility of comparison, campaign and discounts, lack of restrictions such as time and place, ease of payment and generally practicality can be listed (Erdoğan, 2020, p.1304). In this direction, the behavior of consumers has also changed rapidly during the COVID-19 process. Consumers' motives are influential on their consumption decisions, what they are exposed to and how they perceive it (Torun Kayabaşı, 2020, p.21). In the light of this information, in a study conducted on consumers in America, Canada, England, France and Germany, it was stated that four different consumer profiles emerged during the COVID-19 process. These; stockpiling consumers $(35 \%)$, cautious consumers $(27 \%)$, stable consumers (26\%) and guarantor consumers (11\%) (Rogers and Cosgrove, 2020).

As a result of the information obtained on the e-commerce report of OECD (2020), developments and suggestions in e-commerce caused by COVID-19 can be listed as follows: 
- The COVID-19 crisis has accelerated the expansion of e-commerce into new companies, customers and product types. While providing customers with the opportunity to access a wide variety of products from their homes; On the other hand, businesses have provided the opportunity to continue their activities despite the measures of social distance restrictions.

- Despite the differences between countries, the COVID-19 crisis has increased dynamism in the e-commerce environment across countries and has expanded the scope of e-commerce to new companies, consumer segments and products.

- As a result of the COVID-19 crisis, new policy arrangements are also needed due to such new roles of e-commerce for individuals and companies.

- Creating prejudices of consumers towards participation in e-commerce; There has been an experience and relief in matters such as communication, financial access, digital security and privacy, protection of personal information.

- Many of these changes in the e-commerce environment will become permanent due to factors such as the possibility of the epidemic reoccurring and the comfort of online purchasing habits.

- In addition to this information, recommendations regarding e-commerce during and after COVID-19 can be listed as follows:

- Quality, discounted and safe product groups should be expanded to rural areas in order to close the gap between Digital Market segments.

- It should be ensured that vulnerable consumer groups (elderly people, etc.) participate in e-commerce activities by protecting them from unfair business practices and unsafe products.

- It should be ensured that innovative e-commerce business models are created and online business applications remain flexible.

- Transparency should be increased by reducing legal uncertainties in e-commerce and by sharing information.

- Legal and financial incentives should be provided to increase the confidence of SMEs in e-commerce and to offer new sales areas. 
Changes in e-commerce caused by COVID-19 and suggestions that can be applied afterwards are mentioned. Analyzing these changes in favor of online shopping companies and developing strategies will provide profit in the future.

\section{Kaynakça / References}

Akgün, Z., Durmaz, S.S. ve Hacihasanoğlu, P. (2020). Covid-19 salgını sürecinde online alışveriş: genişletilmiş teknoloji kabul modeli ve algilanan kayg perspektifinde bir saha çalışması. International Journal of Disciplines Economics and Administrative Sciences Studies, 6(19), 433-449.

Andrienko, O. (2020). Ecommerce and consumer trends during coronavirus. 15.11 .2020 tarihinde https://www.semrush.com/blog/ecommerce-covid-19/ adresinden erişildi.

Armağan, E. ve Temel, E. (2018). Türkiye'de online kompulsif alışveriş davranışı üzerine ampirik bir çalışma. Dokuz Eylül Üniversitesi Sosyal Bilimler Enstitüsü Dergisi, 20, 621653.

Bhatti, A., Akram, H., Basit, H. M., Khan, A. U., Raza, S. V. ve Bilal, N. M. (2020). ECommerce trends during covid-19 pandemic. International Journal of Future Generation Communication and Networking, 13, 1449-1452.

Cui, Y., Niu, J. ve Tang, L. (2017). Effect of the online shopping value on e-satisfaction and e-loyalty. Economic Management Journal, 6, 9-20.

Demirdöğmez, M., Taş, H. Y. ve Gültekin, N. (2010). Koronavirüsün (Covid-19) eticarete etkileri. OPUS Uluslararası Toplum Araştırmaları Dergisi, 16, 127-145.

Erdoğan, M. G. (2020). Covid-19 döneminde e-ticaret ve dijital reklam yatırımları. Selçuk İletişim Dergisi, 13, 1296-1318.

Güven, H. (2020). Covid-19 pandemik krizi sürecinde e-ticarette meydana gelen değişimler. ASEAD, 7, 251-268.

Kayapınar, Ö., Kayapınar, P. Y. ve Tan, Ö. (2017). Sosyal medya reklamlarına yönelik tüketici algıları ile e-sadakat arasındaki ilişkide markaya yönelik tutumun rolü. Journal of Business Research Türk, 9, 472-494.

Netcomm Suiesse (2020). COVID 19 and e-commerce findings from a survey on online consumers in 9 countries. United Nations Conference On Trade And Development. 16.11.2020 tarihinde, https://unctad.org/system/files/officialdocument/dtlstictinf2020d1 en.pdf adresinden erişildi. 
OECD, (2020). COVID-19 and the retail sector: impact and policy responses. OECD Policy Responses to Coronavirus, 17.11.2020 tarihinde, http://www.Oecd.Org/Coronavirus/Policy-Responses/Covid-19-AndTheRetail-Sector-İmpact-And-Policy-Responses-371d7599 adresinden erişildi.

OECD, (2020). E-commerce in the time of COVID-19. OECD tackling to coronavirus (COVID-19), 17.11.2020 tarihinde, https://www.oecd.org/coronavirus/policy-responses/e-commerce-in-the-time-of-covid-193a2b78e8/ adresinden erişildi.

Rogers, K., ve Cosgrove, A. (2020). Future consumer index: how covid-19 is changing consumer behaviors. 15.11.2020 tarihinde, https://www.Ey.Com/En Gl/Consumer-Products-Retail/How-Covid-19-Could-Change-Consumer-Behavior adresinden erişildi.

Sin, S.S., Nor, K.M. ve Al-Agaga, A. M. (2012). Factors affecting Malaysian young consumers' online purchase intention in social media websites. Social and Behavioral Sciences, 40, 326-333.

Statista (2020). Coronavirus impact on retail e-commerce website traffic worldwide as of June 2020, by average monthly visits. 15.11.2020 tarihinde https://www.statista.com/statistics/1112595/covid-19-impact-retail-e-commerce-site-trafficglobal/ adresinden erişildi.

Telli Danışmaz, A. (2020). Covid-19 salgınının tüketicilerin online alışveriş tercihine etkisi. Sosyal Bilimler Araştırma Dergisi, 9, 83-90.

Torun Kayabaşı, E. (2020). Covıd-19'un piyasalara ve tüketici davranışlarına etkisi. $A S E A D, 7,15-25$.

Tübisad ve Delloitte (2019). E-Ticaretin gelişimi sınırlarn aşılması ve yeni normlar raporu. 17.11.2020 tarihinde, https://www2.deloitte.com/content/dam/Deloitte/tr/Documents/consumer-business/e-ticaretin-gelisimi-sinirlarin-asilmasi-ve-yeni-normlar.pdf adresinden erişildi.

WARC, N. A. (2020). The COVID-19 impact on advertising spend. Visual Capitalist, 16.11.2020 tarihinde, https://www.Visualcapitalist.Com/The-Covid-19-İmpact-OnAdvertising-Spend//adresinden erişildi.

\section{Kaynakça Bilgisi / Citation Information}

Bayır, T. (2021). Koronavirüs (covid-19) ile yeni dijital dünyada değişen tüketici tercihleri. OPUS-Uluslararası Toplum Araştırmaları Dergisi, 17(Pandemi Özel Sayıs1), 3621-3640. DOI: 10.26466/opus.829515 